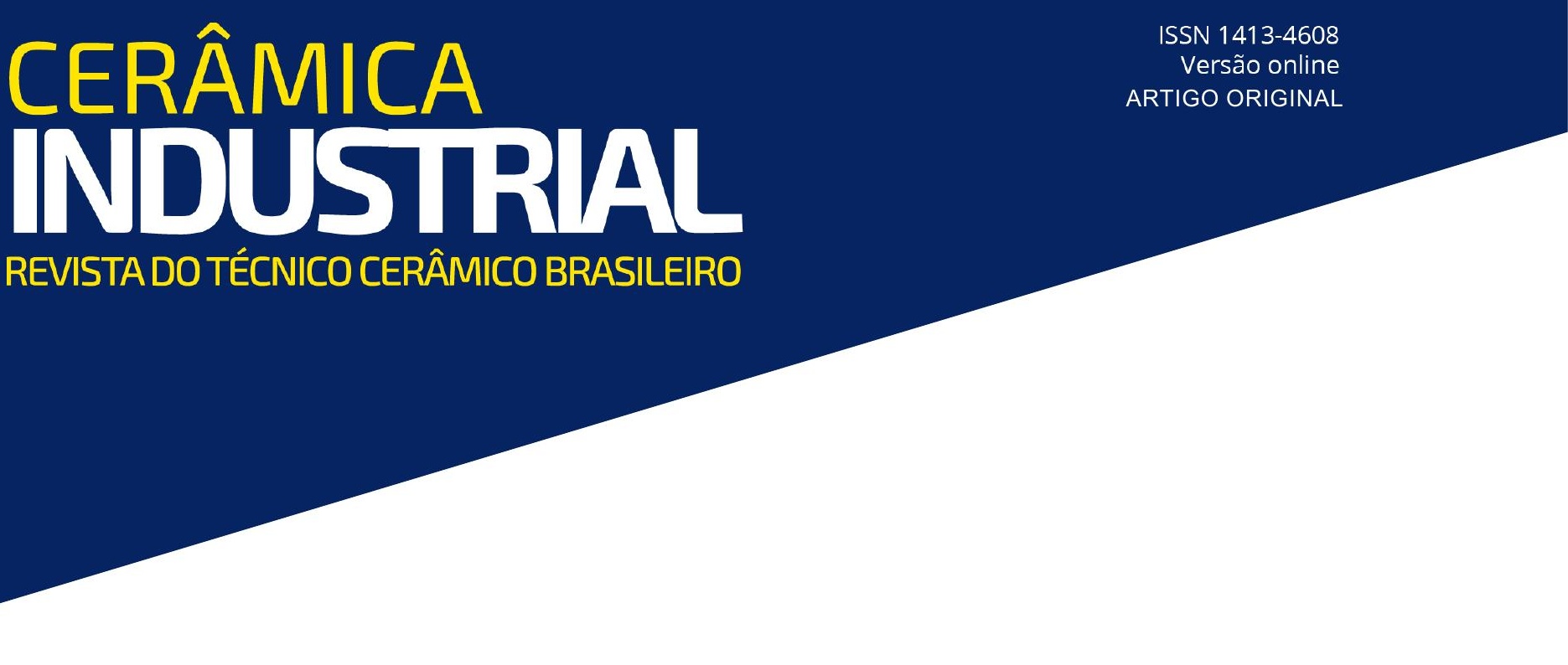

\title{
Esmalte de baixa temperatura à base de óxido de estrôncio para cerâmica vermelha
}

\author{
R. Silveira ${ }^{\text {a* }}$, A. Zacaron ${ }^{\text {a }}$, E. Pezente ${ }^{\text {b }}$, A. Oliveira ${ }^{\text {a }}$, S. Arcaro ${ }^{\text {a }}$, O. R. K. Montedo ${ }^{\text {a }}$, A. De Noni Jr. ${ }^{\text {, }}$ \\ E. Angioletto ${ }^{a}$ \\ a Universidade do Extremo Sul Catarinense, Av. Universitária 1105, Criciúma, SC, 88806-000, Brasil \\ b Omega Colorifício Cerâmico, Rua João De Noni 166, Cocal do Sul, SC, 88845-000, Brasil \\ c Universidade Federal de Santa Catarina, Campus Reitor João David Ferreira Lima, Florianópolis, SC, 88040-900, Brasil \\ *e-mail: ramonsilveirapeyerl@gmail.com
}

\begin{abstract}
Resumo
A cerâmica tradicional é uma arte milenar que fabrica produtos econômicos e necessita ser cada vez mais competitiva. Um relevante avanço no processo produtivo consiste na aplicação de esmaltes em cerâmicas vermelhas. Sob essa perspectiva, o presente trabalho desenvolveu, de forma inovadora, um esmalte com adição de óxido de estrôncio, que apresenta viscosidade de fundido e molhabilidade ideal. A pesquisa foi realizada em duas etapas: na primeira, as fritas comercias, matérias-primas e um substrato cerâmico foram caracterizados; na segunda etapa, desenvolveu-se uma frita e consequentemente seu esmalte. $O$ substrato cerâmico foi caracterizado por análise de difração de raios- $x$ e dilatação térmica. Para o engobe e o esmalte, a seleção e caracterização foram feitas pela dilatação térmica, análise química, aplicação e botão de fusão. Com os esmaltes definidos, foram realizadas as caracterizações de viscosidade de fundido, temperatura de meia-esfera e consequentemente molhabilidade do esmalte. $O$ engobe selecionado não apresentou defeitos superficiais no processo, além de mostrar uma opacidade e alvura adequadas para a deposição do esmalte. Quatro composições dos esmaltes atingiram os objetivos deste trabalho, sendo que os melhores resultados foram encontrados nas composições com $0,25 \% \leq \mathrm{SrO} \% \leq 2,0 \%$. Esse óxido baixou consideravelmente a temperatura de $1056{ }^{\circ} \mathrm{C}$ para $858{ }^{\circ} \mathrm{C}$ e a viscosidade do fundido de 105 para 103,55 dPa.s., melhorando a qualidade de textura, brilho e impermeabilidade, resultando em um esmalte inovador para cerâmica tradicional.
\end{abstract}

Palavras Chave: Esmalte de boro; Óxido de estrôncio; Viscosidade de fundido; Bloco cerâmico; Cerâmica vermelha.

\section{INTRODUÇÃO}

A abundância de matérias-primas naturais, fontes alternativas de energia e disponibilidade de tecnologias existentes nos equipamentos industriais fizeram com que as indústrias cerâmicas brasileiras evoluíssem rapidamente e muitos produtos dos diversos segmentos cerâmicos atingissem nível de qualidade mundial, com apreciável quantidade exportada [1]. O Brasil é um dos principais protagonistas no mercado mundial de revestimentos cerâmicos, ocupando a terceira posição em produção e consumo [2]. O setor de cerâmica vermelha produz atualmente mais de 5 milhões de toneladas por mês, o que corresponde a um faturamento anual de mais de $R \$ 18$ bilhões. A cerâmica vermelha representa $90 \%$ das alvenarias e coberturas construídas no Brasil e corresponde a aproximadamente 
$5 \%$ de toda a indústria da construção civil [3]. Do total das indústrias de cerâmica vermelha, cerca de $36 \%$ fabricam telhas cerâmicas.

$\mathrm{Na}$ busca pela inovação e para a melhoria de qualidade, com o objetivo de satisfazer as atuais exigências estéticas do mercado, o setor da cerâmica vermelha é compelido a pesquisar novas soluções tecnológicas (processo e/ou produto).

Nessa perspectiva, no setor cerâmico de pisos e revestimentos de prensagem a seco, por exemplo, um grande avanço ocorreu com a introdução dos sistemas rápidos de secagem e queima. Referido aperfeiçoamento é consequência de intensas pesquisas e evoluções nos campos da preparação das matérias-primas e uma profunda e decisiva inovação tecnológica do processo e do produto [4]. O setor de cerâmica vermelha também está passando por essa transformação, o que revela a necessidade de maior desenvolvimento de telhas esmaltadas tanto para monoqueima como para biqueima.

Diversos trabalhos têm sido realizados para a utilização de esmaltes na cerâmica vermelha, com o intuito de conferir melhor aspecto e, principalmente, promover a diminuição da permeabilidade [5].

Em geral, os materiais cerâmicos para a construção têm se adaptado ao longo dos séculos às mudanças ocorridas nos sistemas construtivos, interferindo assim na natureza das edificações e na sua vida útil. É o que vem ocorrendo com tijolos e telhas durante milhares de anos. Esse processo deve continuar, embora a variedade de materiais de construção esteja aumentando, enquanto mais e mais novos recursos são descobertos [6].

No setor de esmaltação de telhas, estas recebem uma camada vítrea, que traz várias vantagens, como impermeabilidade, aumento da resistência química, redução no surgimento de fissuras, diminuição do acúmulo das sujeiras que ficam presas no telhado e aumento da durabilidade, dentre outros [7]. Para que esse processo ocorra com o menor número de defeitos, a obtenção de um esmalte com baixa temperatura de fusão, bem como o adequado acoplamento esmalte/suporte, são necessários.

Vale salientar que na indústria de cerâmica vermelha, o processo de queima oscila ao redor de $1000{ }^{\circ} \mathrm{C}$. Essa é uma temperatura baixa quando comparada com outros processos cerâmicos que utilizam esmaltes, o que torna imprescindível o uso de esmaltes específicos para aplicação nessa temperatura.

No histórico do desenvolvimento de esmaltes com baixo ponto de fusão, utilizou-se largamente o chumbo [8,9] e o lítio [10]. Entretanto, nos últimos anos, o chumbo passou a ser substituído em função de sua toxicidade e de apelos ambientais [11]. Por outro lado, diminui-se o uso do lítio por apresentar um custo elevado.

Nesse contexto, o objetivo deste trabalho é desenvolver um esmalte para queima a baixa temperatura, sem a presença de $\mathrm{PbO}$, com uma viscosidade de fundido adequada para proporcionar uma melhor molhabilidade e, consequentemente, um melhor estiramento do vidrado sobre o suporte, aumentando aderência, brilho, impermeabilidade, etc., o que gera alternativas para alavancar o crescimento e aumentar as possibilidades comerciais para esse segmento.

\section{PROCEDIMENTO EXPERIMENTAL}

\subsection{Obtenção do suporte}

A confecção das peças do suporte cerâmico foi realizada utilizando-se as matérias-primas normalmente empregadas no processo industrial de cerâmica vermelha para a fabricação de telhas. A formulação do suporte é mostrada na Tab.1.

Tabela 1. Formulação do suporte

$\begin{array}{cc}\text { Matéria-prima } & \text { Quantidade (\% em massa) } \\ \text { Argila amarela } & 50,0 \\ \text { Argila taguá } & 25,0 \\ \text { Argila preta } & 16,5 \\ \text { Resíduo cerâmico } & 8,5\end{array}$

Os pós homogeneizados das matérias-primas foram compactados uniaxialmente em prensa hidráulica (Gabrielle L4/11OA; $250 \mathrm{kgf} / \mathrm{cm}^{2}$ ). Os compactos foram secos em estufa (Servitech CT-317/B) a 
$110 \pm 1^{\circ} \mathrm{C}$ até massa constante e queimados em forno de queima rápida (Fortelab MC 1200/450) até $900{ }^{\circ} \mathrm{C}$ durante $60 \mathrm{~min}$, com taxa de aquecimento e resfriamento de $15^{\circ} \mathrm{C} / \mathrm{min}$.

A dilatação térmica foi realizada em flexímetro óptico (Expert System Solutions S.R.L Misura Flex ODLT) com taxa de aquecimento de $5^{\circ} \mathrm{C} / \mathrm{min}$. O valor do coeficiente de expansão térmica (CET) do suporte cerâmico foi de $53 \times 10-7^{\circ} \mathrm{C}^{-1}$.

\subsection{Desenvolvimento do engobe}

Para a produção do engobe, utilizou-se uma frita comercial branca de um colorifício da região sul de Santa Catarina, bem como matérias-primas usadas comercialmente, como caulim, quartzo, argila, zirconita, feldspato de lítio e nefelina, e os aditivos carboximetilcelulose (CMC) e tripolifosfato de sódio (TPF) de acordo com a Tab.2. As matérias-primas foram moídas em moinho excêntrico de laboratório (CT-242 Servitech) com bolas de alumina. Após a moagem, a barbotina foi peneirada em peneira de malha 325 mesh $(45 \mu \mathrm{m})$.

Tabela 2. Formulação do engobe

\begin{tabular}{cc} 
Matéria-prima & Quantidade (\% em massa) \\
Frita Branca & 60,0 \\
Caulim & 5,0 \\
Feldspato de Lítio & 18,0 \\
Argila Branca & 8,0 \\
Argila Plástica & 3,5 \\
Zirconita & 5,0 \\
Tripolifosfato de Sódio & 0,3 \\
Carboximetilcelulose & 0,2 \\
\hline
\end{tabular}

O resíduo de cada moagem foi de 0,5 a 1,0\%. A densidade da formulação do engobe foi ajustada para atingir o valor de 1,5 g/ $\mathrm{cm}^{3}$, com o auxílio de um picnômetro (Servitech CT-295). Além disso, também foi realizada análise visual de cor, opacidade e aderência do botão no suporte. $O$ tempo de escoamento das suspensões para aplicação foi medido em copo Ford $n^{\circ} 4$ (Servitech), obtendo-se valores em torno de $10 \mathrm{~s}$. A aplicação do engobe no suporte cerâmico foi realizada em cabine de aplicação à pistola (Servitech CT 269).

\subsection{Desenvolvimento da Frita}

O ponto de partida para a formulação da frita de estudo foi a seleção de uma frita comercial fundente sem chumbo (Frita OFA 04), cuja composição química é apresentada na Tab.3. A frita OFA 04 foi escolhida por possuir características potenciais para aplicação ao processo de telhas esmaltadas.

Tabela 3. Formulação da frita OFA04

\begin{tabular}{cc} 
Óxido & Teor (\% em massa) \\
$\mathrm{Na}_{2} \mathrm{O}$ & 7,28 \\
$\mathrm{Fe}_{2} \mathrm{O}_{3}$ & 0,06 \\
$\mathrm{TiO}_{2}$ & 0,03 \\
$\mathrm{SiO}_{2}$ & 77,80 \\
$\mathrm{MgO}^{2}$ & 0,09 \\
$\mathrm{Al}_{2}$ & 5,22 \\
$\mathrm{CaO}$ & 1,36 \\
$\mathrm{~B}_{2} \mathrm{O}_{3}$ & 8,16 \\
\hline
\end{tabular}

A composição da frita comercial foi modificada após cálculos estequiométricos. A nova composição foi selecionada pelo seu respectivo ponto amolecimento, escorrimento, dilatação e textura/brilho, este último servindo de limite para encerramento dos testes preliminares. Os parâmetros primordiais para essa seleção inicial eram a temperatura de fusão $\mathrm{T} \leq 1000^{\circ} \mathrm{C}$ com uma dilatação térmica $<53 \times$ $10^{-7}{ }^{\circ} \mathrm{C}^{-1}$. A composição da frita comercial foi modificada a partir das seguintes matérias-primas: ácido bórico, quartzo, albita, carbonato de sódio, caulim, nitrato de potássio, óxido de zinco, carbonato de bário e calcita. A composição química da frita final obtida (OFA04/1 modificada) foi avaliada por 
fluorescência de raios $X$ por dispersão de comprimento de onda (WDXRF, Panalytical modelo Axios Max) e é mostrada na Tab.4. A determinação de $\mathrm{B}_{2} \mathrm{O}_{3}$ foi realizada via espectrometria de emissão óptica com plasma indutivamente acoplado - ICP-OES (Agilent 720).

Tabela 4. Formulação da frita OFA04/1 modificada

\begin{tabular}{cc} 
Óxido & Teor (\% em massa) \\
$\mathrm{Na}_{2} \mathrm{O}+\mathrm{K}_{2} \mathrm{O}$ & 5,5 \\
$\mathrm{Al}_{2} \mathrm{O}_{3}$ & 7,0 \\
$\mathrm{SiO}_{2}$ & 51,3 \\
$\mathrm{~B}_{2} \mathrm{O}_{3}$ & 30,6 \\
$\mathrm{CaO}$ & 1,7 \\
$\mathrm{BaO}$ & 1,4 \\
$\mathrm{ZnO}$ & 1,7 \\
\hline
\end{tabular}

\subsection{Desenvolvimento do Esmalte}

Com o objetivo de obter o melhor acordo de acoplamento suporte/vidrado e viscosidade de fundido adequada, composições de esmalte foram preparadas utilizando-se a frita OFA04/1 modificada como base e acrescentando-se óxido de cálcio e óxido de estrôncio (a partir da calcinação do carbonato de cálcio e de estrôncio), como mostrado na Tab.5. Vale salientar que, neste trabalho, procurou-se desenvolver um esmalte para ser aplicado a temperaturas abaixo de $1000^{\circ} \mathrm{C}$. Em todas as formulações da Tab.5, foram utilizados sobre a quantidade pesada (\% em massa): 0,3\% de CMC (Carboximetilcelulose), $0,25 \%$ de TPF e $45 \%$ de água.

Tabela 5. Formulações dos esmaltes estudados

\begin{tabular}{|c|c|c|c|c|c|c|}
\hline \multirow{2}{*}{ Material } & \multicolumn{6}{|c|}{ Formulações dos esmaltes estudados (\% em massa) } \\
\hline & 4 & 6 & 7 & $4 \mathbf{X}$ & $6 \mathrm{X}$ & $7 \mathbf{7 X}$ \\
\hline Frita OFA04/1 & 92,75 & 92,75 & 92,50 & 92,50 & 92,50 & 92,00 \\
\hline Óxido de cálcio & 0,25 & & 0,25 & 0,50 & & 0,50 \\
\hline Óxido de estrôncio & & 0,25 & 0,25 & & 0,50 & 0,50 \\
\hline $\begin{array}{l}\text { Caulim branco } \\
\text { lavado }\end{array}$ & 7 & 7 & 7 & 7 & 7 & 7 \\
\hline
\end{tabular}

As matérias-primas foram moídas a úmido em moinho excêntrico de laboratório (Servitech CT-242) até obter-se resíduo de moagem de 3 a $4 \%$ em peneira com abertura $45 \mu \mathrm{m}$ (\#325 mesh). A densidade das suspensões foi ajustada para atingir o valor de 1,60 $\pm 0,02 \mathrm{~g} / \mathrm{cm}^{3}$ e tempo de escoamento de $13 \mathrm{~s}$ com auxílio de um copo Ford $\mathrm{n}^{\circ} 4$ (Servitech). Além disso, foi realizada análise visual de cor, brilho, opacidade, transparência, textura e fundência (maior escorrimento) e aderência do botão no suporte.

Para a comparação da viscosidade de fusão (método do "botão de escorrimento"), foi utilizado um anel metálico cilíndrico de aço inox com as seguintes dimensões: diâmetro externo de $25 \mathrm{~mm}$, diâmetro interno de $20 \mathrm{~mm}$ e altura de $25 \mathrm{~mm}$.

Inicialmente, preparou-se um suporte cerâmico poroso com escala impressa. Foi depositado $3 \mathrm{~g}$ da amostra moída (suspensão) no anel cilíndrico, posicionado sobre o suporte. $O$ anel cilíndrico (molde) foi previamente untado com óleo vegetal na parte interna para evitar a aderência da amostra às paredes internas do molde. Aguardou-se tempo suficiente para que ocorresse a fixação da amostra no suporte, por meio da absorção da água da suspensão, até consistência suficiente que permitisse a retirada cuidadosa do anel. Apoiou-se o substrato (com os botões de escorrimento) em uma base refratária proporcionando um ângulo de inclinação de $70 \pm 3^{\circ}$ e queimou-se em forno mufla à temperatura de $965 \pm 1{ }^{\circ} \mathrm{C}$ com patamar de queima de $1 \mathrm{~h}$. Após, retirou-se do forno e procedeu-se a leitura do comprimento do escorrido diretamente na escala impressa no substrato cerâmico.

O coeficiente de expansão térmica dos esmaltes e de acoplamento suporte/vidrado foram determinados em um flexímetro óptico (Expert System Solutions S.R.L Misura Flex ODLT), com taxa de aquecimento de $5^{\circ} \mathrm{C} / \mathrm{min}$. O coeficiente de expansão térmica e as temperaturas de acoplamento foram determinados a partir das curvas resultantes. A partir da curva de dilatação também foi possível obter os valores de temperatura de transição vítrea (Tg) e de amolecimento (Ta). Além disso, 
amostras em pó de esmaltes selecionados foram submetidas à dilatometria óptica para se determinar as temperaturas de esfera, meia esfera e fusão. Para isso, o experimento foi realizado a uma taxa de aquecimento de $5{ }^{\circ} \mathrm{C} / \mathrm{min}$ até a fusão, usando-se o microscópio de aquecimento/dilatômetro óptico (Expert System Solutions ODHT). Com base nos resultados da análise térmica, foi possível determinar as curvas de viscosidade em função da temperatura do vidro usando a equação de Vogel-FulcherTammann [12-14], Equação 1.

$$
\log \left(\eta_{T}\right)=A+\left(-\frac{B}{\left(T-T_{0}\right.}\right)
$$

Equação 1

Onde A, B e T0 são constantes do material. Esses valores foram obtidos a partir dos resultados de análise térmica, resultado em um gráfico de viscosidade em relação à temperatura.

\section{RESULTADOS E DISCUSSÃo}

\subsection{Desenvolvimento do engobe}

Inicialmente, a partir do valor do CET do suporte, foi desenvolvida a formulação do engobe. Para isso, utilizou-se a dilatação térmica apresentada pela base cerâmica $\left(53 \times 10^{-7}{ }^{\circ} \mathrm{C}^{-1}\right)$ como requisito para a seleção das fritas comerciais e matérias-primas queimadas. A composição do engobe formulado se apresentou adequada ao propósito, já que se obteve CET de $45 \times 10^{-7}{ }^{\circ} \mathrm{C}^{-1}$, conforme mostrado na Fig. 1 .

O engobe aplicado sobre o suporte cerâmico apresentou aspecto visual branco e opaco. Pode-se inferir que a opacidade alcançada ocorre devido à presença do silicato de zircônio na formulação e ausência de elementos colorantes como ferro, manganês e titânio. Além disso, o engobe apresentou textura adequada para o processo de biqueima.

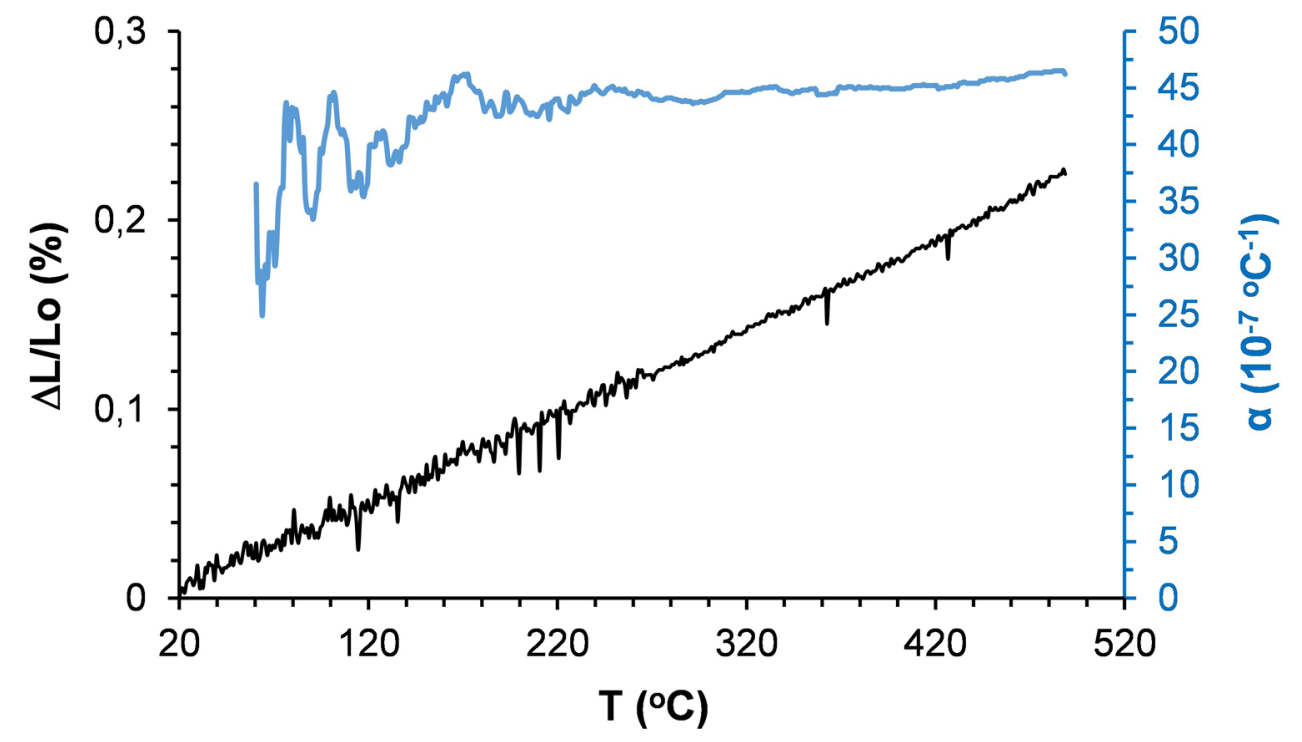

Figura 1. Dilatação térmica do engobe formulado

\subsection{Desenvolvimento da frita}

Da mesma forma que o engobe, utilizou-se o CET do suporte cerâmico $\left(53 \times 10^{-7}{ }^{\circ} \mathrm{C}^{-1}\right)$ como requisito para a seleção das fritas comerciais e matérias-primas para a obtenção da frita. Estudos preliminares foram realizados para avaliar as características das fritas comerciais. Apesar de algumas fritas comerciais apresentarem CET compatível com o suporte cerâmico, as mesmas apresentaram alto ponto de fusão e, por isto, foram descartadas.

Desta forma, foi desenvolvida uma nova frita transparente, fundente e sem a presença de óxido de chumbo (normalmente utilizado para aumentar as características fundentes e o brilho). A composição 
química resultante é apresentada na Tab.6. Observa-se na tabela que a composição química da frita apresenta majoritariamente óxido de silício $\left(\mathrm{SiO}_{2}\right)$, óxido de boro $\left(\mathrm{B}_{2} \mathrm{O}_{3}\right)$ e alumina $\left(\mathrm{Al}_{2} \mathrm{O}_{3}\right)$.

Tabela 6. Composição química da frita

\begin{tabular}{cc}
\hline Óxido & Teor em massa (\%) \\
$\mathrm{K}_{2} \mathrm{O}$ & 2,8 \\
$\mathrm{Al}_{2} \mathrm{O}_{3}$ & 6,3 \\
$\mathrm{SiO}_{2}$ & 51,3 \\
$\mathrm{~B}_{2} \mathrm{O}_{3}$ & 31,0 \\
$\mathrm{CaO}$ & 1,7 \\
$\mathrm{BaO}$ & 1,4 \\
$\mathrm{ZnO}$ & 1,7 \\
$\mathrm{Fe}_{2} \mathrm{O}_{3}$ & 0,3 \\
$\mathrm{MgO}$ & 0,2 \\
$\mathrm{Na}_{2} \mathrm{O}$ & 2,7 \\
$\mathrm{TiO}_{2}$ & 0,1 \\
$\mathrm{Li}_{2} \mathrm{O}$ & 0,6 \\
$\mathrm{SrO}$ & 0,1 \\
\hline
\end{tabular}

\subsection{Desenvolvimento do esmalte}

A partir da frita formulada foram produzidos os esmaltes. A Fig.2 apresenta uma fotografia dos botões de fusão dos esmaltes nomeados $4,4 X, 6,6 X, 7$ e $7 X$. O esmalte 4 é composto pela frita desenvolvida, óxido de cálcio e caulim. Já o esmalte $4 X$ foi produzido dobrando-se a quantidade de óxido de cálcio. No esmalte 6 foi utilizada a frita desenvolvida, o óxido de estrôncio e caulim. O esmalte $6 \mathrm{X}$ foi produzido dobrando-se a quantidade de óxido de estrôncio (0,50\%). O esmalte 7 é composto pela frita desenvolvida, óxido de cálcio, óxido de estrôncio e caulim. Já o esmalte $7 X$ foi produzido dobrando-se a quantidade de óxido de cálcio e óxido de estrôncio.

Observa-se, pela análise da Fig.2, a extensão do escorrimento dos esmaltes formulados a $965^{\circ} \mathrm{C}$ por 60 min de patamar de queima. Aparentemente, nessa temperatura ocorre o início da fusão em todos os esmaltes testados. Vale ressaltar que o esmalte 4 apresentou um início de escorrimento indicando ser possível o uso do óxido de cálcio para esta formulação de esmalte.

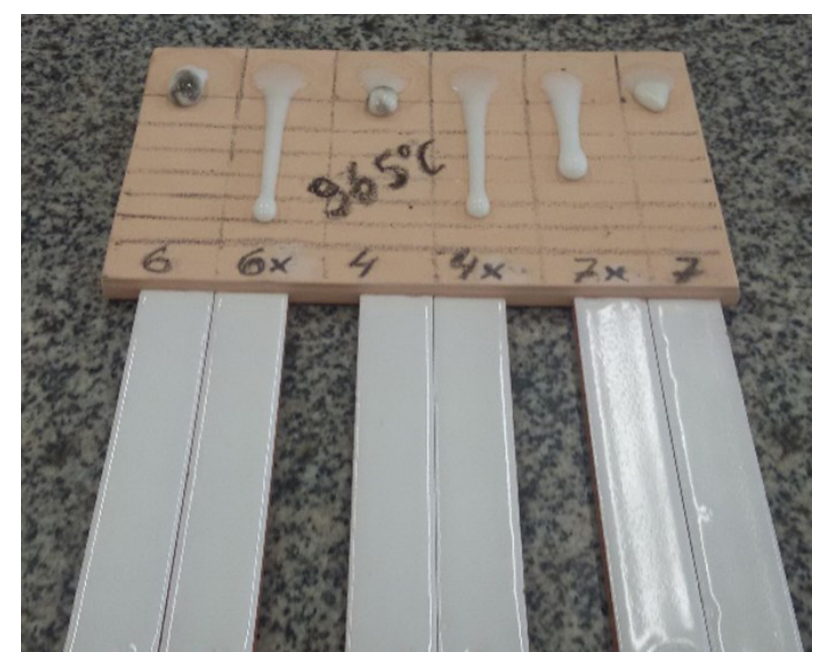

Figura 2. Aspecto de fusão dos esmaltes $4,4 X, 6,6 X, 7$ e $7 X$

No esmalte 6 observa-se também um início de fluidez. Já o esmalte 7 também apresentou boa fluidez. Posteriormente, um teste visual complementar de textura, brilho, ausência de poros e estiramento do vidrado determinou a seleção da melhor opção dos esmaltes. Dessa forma, observa-se que o melhor resultado de fluidez foi do esmalte 6X (Fig.2). Observa-se ainda que no aspecto de aplicação sobre a peça, o esmalte $6 \mathrm{X}$ manteve todas as características estéticas após a queima. As peças aplicadas 
com o esmalte $4 \mathrm{X}$ também apresentaram ótima textura. Por outro lado, as peças onde se aplicou o esmalte $7 \mathrm{X}$ apresentaram textura com qualidade inferior as anteriores sendo observada a presença pin holles (de pequenos poros). Esse defeito nos esmaltes ocorre devido ao excesso de fusibilidade ou excesso de moagem do vidrado que causa uma redução demasiada do tamanho de partícula [5].

Na Tab.7 são apresentados os valores de CET dos Esmaltes 4, 4X, 6, 6X, 7 e 7X, obtidos a partir das curvas de dilatação na faixa de temperatura de 25 a $325^{\circ} \mathrm{C}$. Pode ser constatado que os valores de CET dos esmaltes ficaram entre 43,0 e $53,0 \times 10^{-7}{ }^{\circ} \mathrm{C}^{-1}$, que são adequados considerando-se os valores de CET do engobe e do suporte. Estes valores poderiam permitir um bom acordo dilatométrico com o suporte, uma vez que se busca no esmalte um valor de CET menor do que aquele do substrato. Isso proporciona à camada vidrada, no resfriamento, ficar em compressão, o que aumenta a resistência a gretagem [4].

Tabela 7. Valores de CET dos Esmaltes 4, 4X, 6, 6X, 7 e 7X

\begin{tabular}{cc} 
Esmalte & CET $\left(\times \mathbf{1 0}^{-\mathbf{7}} \mathbf{C}^{-1}\right)$ \\
4 & 45,5 \\
$4 X$ & 50,4 \\
6 & 44,7 \\
$6 X$ & 51,0 \\
7 & 43,0 \\
$7 X$ & 53,2 \\
Engobe & 45,0 \\
Suporte & 53,0 \\
\hline
\end{tabular}

Os valores de CET dos esmaltes 4X, 6X e 7X aumentaram em comparação aos respectivos esmaltes 4, 6 e 7. Dentre os fatores determinantes para a escolha do esmalte, pode-se salientar fatores qualitativos, como o escorrimento, o brilho e ausência de pin holles. Dentre os esmaltes testados, a composição $6 \mathrm{X}$ atendeu plenamente todos esses aspectos. Entretanto, pretendia-se baixar ainda mais a temperatura de queima do esmalte. Isso foi alcançado por meio de uma nova composição baseada na composição 6X, aumentando-se o teor de SrO de 0,5 para 2,0\% e reduzindo-se o teor de frita OFA04/1 de 92,5 para $91,0 \%$ (teores em \% massa), obtendo-se assim a composição 6X4. O CET desta composição foi de $51,6 \times 10^{-7}{ }^{\circ} \mathrm{C}^{-1}$, o que indica a possibilidade de utilização com baixo risco de gretagem do vidrado.

Nesse sentido, foram realizados ensaios de acoplamento esmalte-suporte dos esmaltes que tiveram os melhores resultados de dilatação térmica. A Fig.3 apresenta os acoplamentos para os Esmaltes 6 , 6X e 6X4.

Inicialmente, foi realizado o ensaio de fleximetria ( $3 a$, 3c e 3e), onde foi possível determinar a temperatura de acoplamento esmalte-suporte.

As temperaturas obtidas foram de $565^{\circ} \mathrm{C}$ para o esmalte $6,540{ }^{\circ} \mathrm{C}$ para o esmalte $6 \mathrm{X}$ e $560{ }^{\circ} \mathrm{C}$ para o esmalte $6 \mathrm{X} 4$. A partir das temperaturas de acoplamento, foram então realizados os ensaios de dilatometria do suporte e do esmalte. As curvas foram sobrepostas e o $\Delta C$ ( variação de contração) pode ser calculado. Dessa forma, observando-se os acoplamentos, nota-se que o esmalte 6 (Fig.3b) se apresenta sob efeito de compressão $(\Delta C=+0,114 \%)$, o que indica que o esmalte possui resistência à gretagem. Dobrando-se a quantidade de SrO, o esmalte 6X (Fig.3d) apresenta uma leve tendência ao gretamento, ou seja, $\Delta C=-0,003 \%$, sendo um esmalte sob efeito da tração. No Esmalte 6X4 (Fig.3f), onde foi aumentado em 4 vezes a quantidade de $\mathrm{SrO}$, o esmalte mostra uma forte tendência a gretagem $(\Delta C=-0,114 \%)$, ou seja, esmalte sob efeito da tração.

A Tab.8 mostra as temperaturas características (sinterização $\left(\mathrm{T}_{\text {sint }}\right)$, transição vítrea $\left(\mathrm{T}_{\mathrm{g}}\right)$, de amolecimento $\left(T_{a}\right)$, de esfera $\left(T_{\text {esfera }}\right)$ e de meia esfera ( $\left.T_{\text {meia esfera }}\right)$ e temperatura de fusão $\left(T_{\text {fusão }}\right)$ ) dos esmaltes, obtidos a partir das curvas de amolecimento realizadas por ensaios de dilatometria óptica. Além disso, apresenta o valor típico de viscosidade para essas temperaturas [15]. 


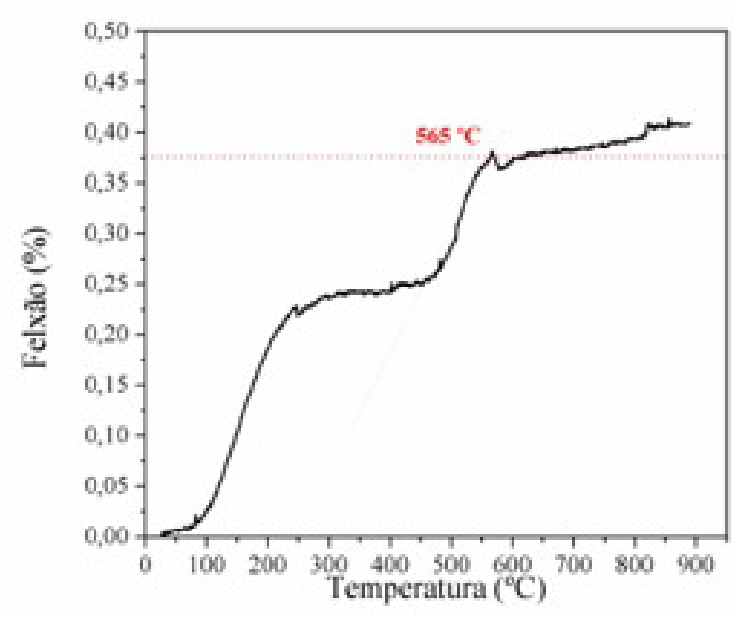

(a)

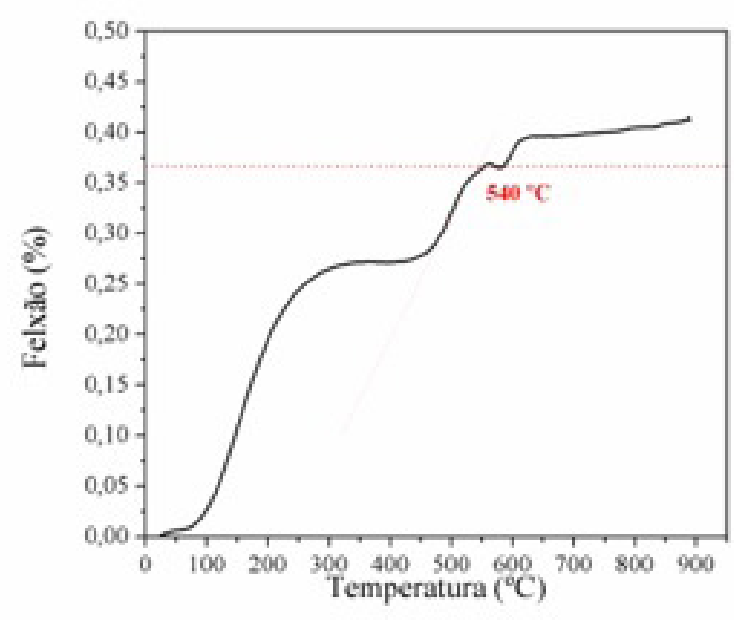

(c)

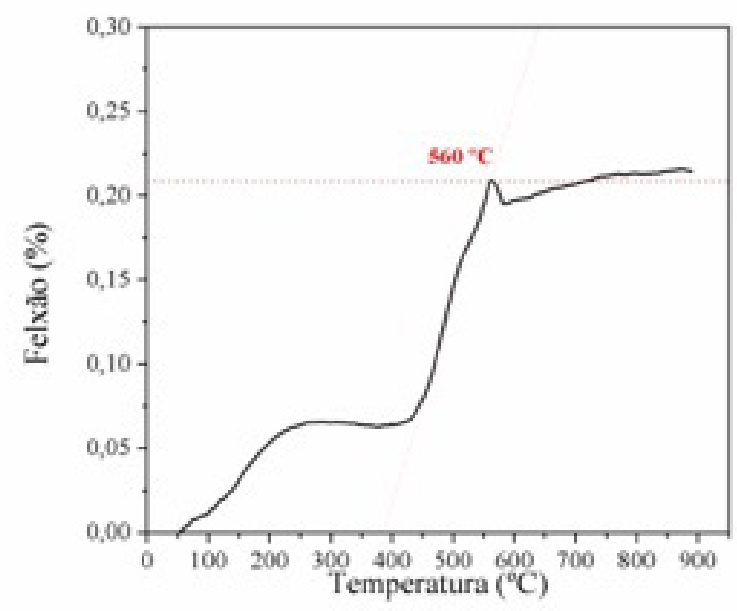

(e)

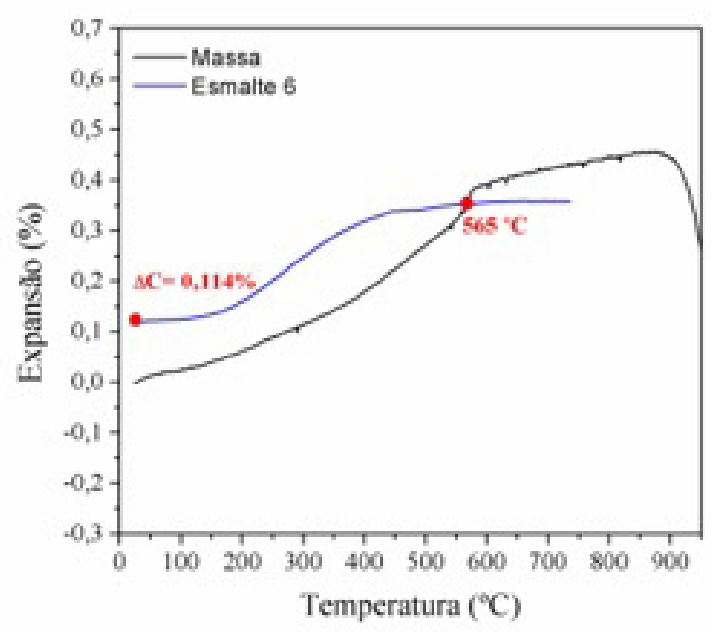

(b)

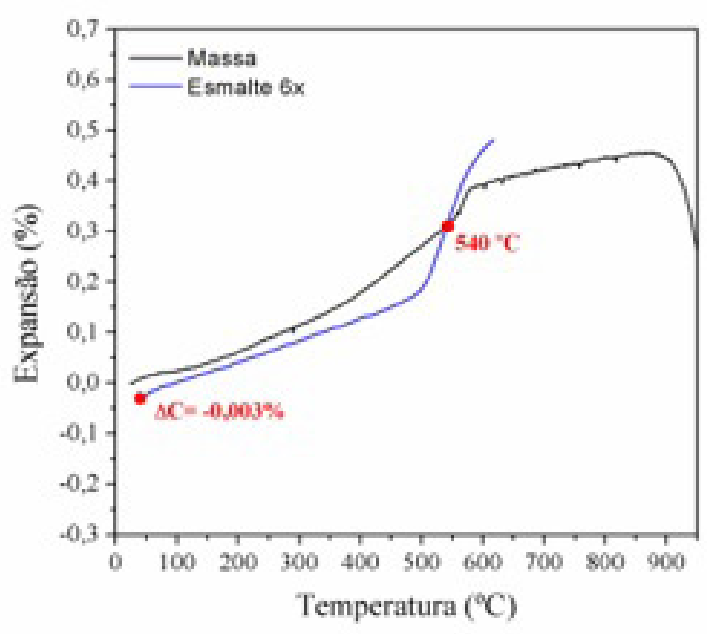

(d)

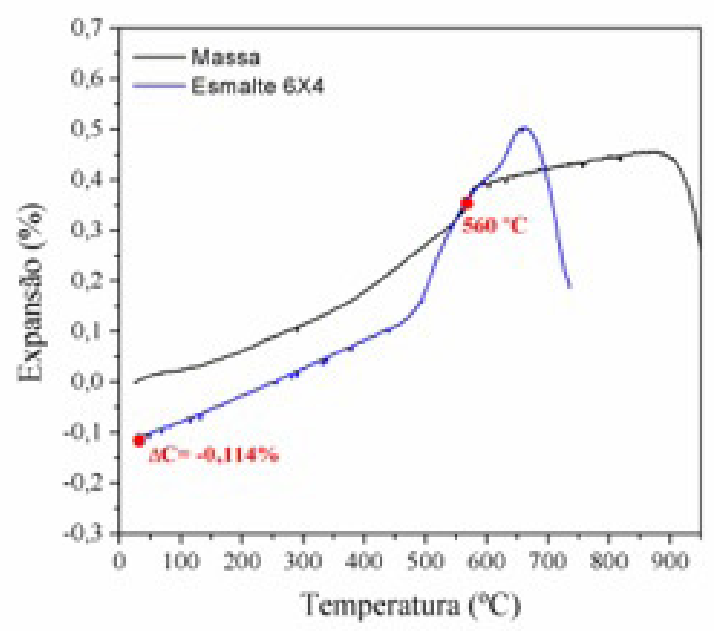

(f)

Figura 3. Curvas de fleximetria e expansão térmica massa/vidrado: (a) e (b) esmalte 6, (c) e (d) esmalte 6X, (e) e (f) esmalte $6 \mathrm{X} 4$ 
Tabela 8. Temperaturas características dos esmaltes

\begin{tabular}{cccccc} 
& $\log \mathbf{n}(\mathbf{d P a . s})$ & \multicolumn{4}{c}{$\mathbf{T}\left({ }^{\circ} \mathbf{C}\right)$} \\
\cline { 3 - 6 } & 12 & Esmalte $\mathbf{4 X}$ & Esmalte $\mathbf{X X}$ & Esmalte $\mathbf{7 X}$ & Esmalte 6X4 \\
$\mathrm{T}_{\mathrm{g}}$ & 10,8 & 689 & 681 & 682 & 480 \\
$\mathrm{~T}_{\text {sint }}$ & 9,25 & 708 & 702 & 717 & 669 \\
$\mathrm{~T}_{\mathrm{a}}$ & 5,1 & 958 & 705 & 843 & 675 \\
$\mathrm{~T}_{\text {esfera }}$ & 3,55 & 1056 & 933 & 957 & 816 \\
$\mathrm{~T}_{\text {meia esfera }}$ & 1 & 1131 & 1035 & 1020 & 858 \\
$\mathrm{~T}_{\text {fusão }}$ & & 1101 & 1065 & 903 \\
\hline
\end{tabular}

A partir dos resultados dos ensaios térmicos da Tab.8, foram confeccionadas as curvas do comportamento da viscosidade em função da temperatura. As curvas são apresentadas na Fig.4. Os valores de log $\mu$ (viscosidade) foram fixados próximos aos valores encontrados na literatura (valores teóricos dos pontos fixos e intervalos de viscosidade encontrados por Navarro [15], sendo a temperatura a variável de resposta).

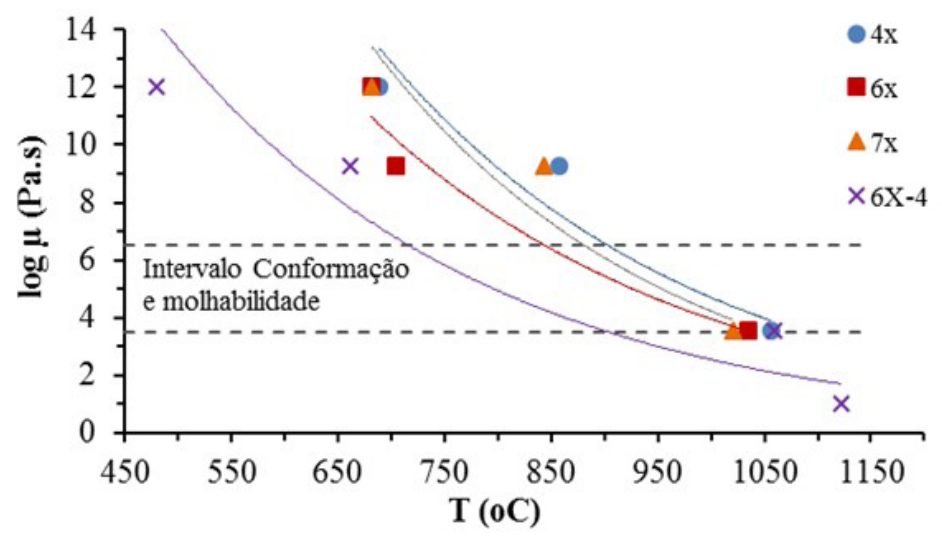

Figura 4. Curvas de viscosidade das formulações $4 X, 6 X, 7 X$ e $6 X 4$

Ao se analisar o comportamento plástico-viscoso de um esmalte, sabe-se que, quando tratados a altas temperaturas, é possível trabalhar em uma ampla faixa térmica. Navarro [15] indica, para os vidros, a faixa de viscosidade de 104 até $106 \mathrm{dPa}$.s para trabalhabilidade adequada para estiramento. O esmalte 6 X4 apresenta o início da trabalhabilidade a temperatura mais baixa $\left(816^{\circ} \mathrm{C}\right)$, em relação aos esmaltes $6 \mathrm{X}\left(933^{\circ} \mathrm{C}\right), 7 \mathrm{X}\left(957^{\circ} \mathrm{C}\right)$ e $4 \mathrm{X}\left(948^{\circ} \mathrm{C}\right)$. Assim, esses resultados corroboram no sentido de demostrar que os esmaltes, desenvolvidos utilizando a adição de óxido de estrôncio estão dentro da faixa de trabalhabilidade adequada a temperaturas abaixo de $1000^{\circ} \mathrm{C}$. Esses resultados também corroboram com o observado na Fig.2, onde o vidrado aparece perfeitamente estirado, com brilho e textura característicos de um esmalte comercial.

Além disso, devido às características mais fundentes do esmalte $6 \times 4$, a queima poderia ser realizada na faixa de 700 até $900^{\circ} \mathrm{C}$, o que seria ainda mais interessante e promissor quando se trata de cerâmica vermelha. Entretanto, o teor de SrO adicionando é 4 vezes maior em relação ao esmalte $6 \mathrm{X}$, o que levou também a um valor de viscosidade de fundido perto da zona de molhabilidade (104 dPa.s). Todavia, conforme observado na Fig.3 $(\Delta C=-0,114)$, esse esmalte possui forte tendência à gretagem. Situação que deve ser evitada.

Dessa forma, é recomendado utilizar quantidades menores de adição de óxido de estrôncio (do que a utilizada na formulação 6X4) para se permanecer com viscosidade próxima ao intervalo de conformação (zona de trabalhabilidade/molhabilidade). Esse resultado é possível de se obter a partir da formulação $6 \mathrm{X}$, ou seja, $\mu=104$ a $106 \mathrm{dPa}$.s, condição em que não ocorreria gretagem $(\Delta C=-0,03)$ . Essa constatação também pode ser visualizada na Figura 2, onde são mostradas as peças com o esmalte aplicado e queimado. Na Fig.5 são apresentadas as características da dilatação em função da viscosidade do fundido para Esmalte 6X4. 


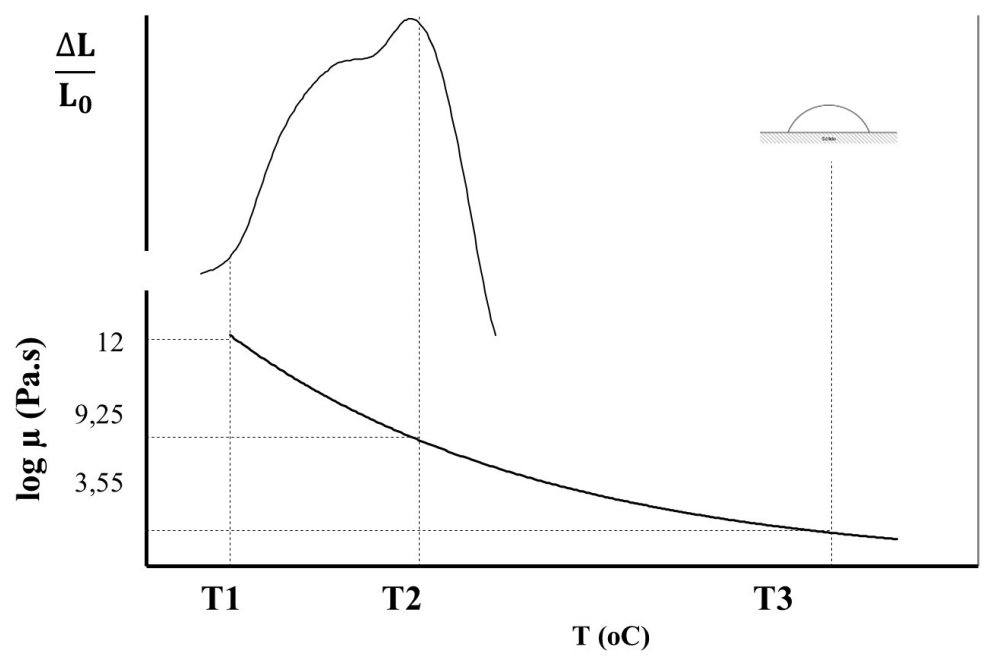

Figura 5. Gráfico da dilatação vs viscosidade do fundido para o Esmalte 6X4

O gráfico foi obtido a partir da correlação das temperaturas características da Tab.8 e da curva de viscosidade (Fig.4). Observa-se que o esmalte $6 X 4$ apresenta $T_{1}=480{ }^{\circ} \mathrm{C}$ a uma viscosidade de $1012 \mathrm{dPa}$.s, que pode ser considerada dentro do intervalo de relaxação ou requeima. Neste intervalo de temperatura, o esmalte começa a passar da fase sólida para a fase líquida, isto é, com o aumento de temperatura o material fica gradativamente mais amolecido. $\mathrm{A}_{2}=675^{\circ} \mathrm{C}$, o esmalte apresenta uma viscosidade de 109,25 dPa.s, o que indica que, a partir deste ponto, o amolecimento do vidrado ocorre a temperatura tão elevada que o corpo de prova se deforma totalmente. $\mathrm{A}_{3}=858{ }^{\circ} \mathrm{C}$, o esmalte 6X4 apresenta viscosidade de 103,55 dPa.s, o que Navarro [15] aponta como estar dentro do intervalo de conformação e muito próximo do ponto de imersão, onde a viscosidade é indicada como $104 \mathrm{dPa}$.s, conhecido como intervalo de molhabilidade do vidro.

\section{CONCLUSÕES}

Neste trabalho foi desenvolvido um esmalte para ser utilizado a baixas temperaturas e aplicado ao setor de cerâmica vermelha. Para isso, estudos detalhados de composição e viscosidade foram realizados. Desenvolveu-se um engobe com as características que possibilitaram um adequado acoplamento entre o substrato de cerâmica vermelha e o vidrado.

O engobe formulado possibilitou eliminar os defeitos superficiais de formação da peça, apresentando ainda opacidade adequada e melhor superfície para a deposição do esmalte. Os esmaltes desenvolvidos mostraram que, como diferencial, o uso do óxido de estrôncio baixa consideravelmente a temperatura de trabalho e a viscosidade do fundido, melhora a molhabilidade e proporciona um apropriado estiramento do esmalte e, consequentemente, coeficiente de dilatação térmica adequado (menor do que $53 \times 10^{-7}{ }^{\circ} \mathrm{C}^{-1}$ ) para a aplicação em substrato de cerâmica vermelha. Os esmaltes aplicados apresentaram, após a queima, cor, brilho, opacidade e/ou transparência adequadas para o substrato testado. Dentre os esmaltes desenvolvidos, o 6X4 apresentou a menor temperatura de trabalho e viscosidade de fundido, perto da zona de trabalhabilidade (molhabilidade). Este esmalte possui $4 \mathrm{X}$ mais estrôncio que o esmalte da composição 6X. Todavia, no caso do 6X4, ocorreu um incremento no coeficiente de dilatação térmica, ocasionando o defeito de gretagem, o que não é desejado. Assim, pode-se trabalhar com quantidades menores de adição de óxido de estrôncio ao esmalte para se permanecer próximo à zona de trabalhabilidade (molhabilidade) e com coeficiente de expansão térmica adequado para que não ocorra o defeito de gretagem, obtidos com a formulação 6X. Dessa maneira foram utilizadas variações nas adições de óxido de estrôncio aos esmaltes à base de boro de forma a atender os quesitos de qualidade exigidos, com custos muito competitivos. 


\section{AGRADECIMENTOS}

Os autores agradecem a CAPES, CNPq (processo n. 308669/2016-9), UNESC e Omega Colorifício Cerâmico pelo suporte prestado.

\section{REFERÊNCIAS}

[1] Associação Brasielira de Cerâmica, ABCERAM, Números do Setor, 2019. https://abceram.org.br/numeros-do-setor/

[2] Associação Nacional dos Fabricantes de Cerâmica para Revestimentos, Louças Sanitárias e Congêneres, ANFACER, Panorama Mundial, 2019. https://anfacer.org.br/numeros-do-setor

[3] Associação Nacional da Indústria Cerâmica, ANICER, Dados do setor, 2019. https://www.anicer.com.br/anicer/setor/

[4] Dutra, R.P.S.; Varela, M.L.; Nascimento, R.M.; Gomes, U.U.; Martinelli, A.E.; Paskocimas, C.A. Estudo comparativo da queima rápida com a queima tradicional nas propriedades de materiais cerâmicos de base argilosa. Cerâmica, v. 55, n. 333, p. 100-105, 2009. https://doi.org/10.1590/s0366-69132009000100014

[5] Felíu, C., et al. "Analisis de algunos factores relacionados con la degradación por abrasión de baldosas cerámicas esmaltadas." Congreso mundial de la calidad del azulejo y del pavimento cerámico (QUALICER). 1990.

[6] Röhrs, M. A produção de cerâmica vermelha: entre a tradição e o desafio. Cerâmica Industrial, v. 21, n. 1, p. 30-36, 2016. https:// dx.doi.org/10.4322/cerind.2016.003

[7] Betancourt-Parra, S.; Domínguez-Ortiz, M.A.; Mosquera-Palacio, D.M.; Herrera-Guerra, J.; Ríos-Rendón, C.M.; Villa, C.E. Deposición de capas funcionales sobre esmaltes cerámicos mediante la técnica sol-gel (revisión), Ingenius. Revista de Ciencia y Tecnología, n. 21, p. 9-20, 2019. https://doi.org/10.17163/ings.n21.2019.01.

[8] Bruguera, Jordi. Manual Práctico de Cerámica. [S.I.]: Ediciones Omgega S.A.,1986.

[9] Andreola, F. Reformulação de um Esmalte Cerâmico Industrial Utilizando Resíduos Beneficiados em Substituição de Fritas e Matérias-primas Naturais. Cerâmica Industrial, 18 (5-6) Setembro/Dezembro, 2013.

[10] Song, D., Tang, R., Yang, F., Qiao, Y., Sun, J., Jiang, J., \& Ma, A. (2018). Development of high-performance enamel coating on grey iron by low-temperature sintering. Materials, 11(11), 2183.

[11] Franceschini, F.G. "Desenvolvimento de um revestimento esmaltado à base de borofosfato de alumínio para a liga AISi ${ }_{9} \mathrm{Cu}_{3}$ e avaliação do acoplamento suporte/esmalte." (2020).

[12] Nascimento, M.L.F.; Aparicio, C. Data classification with the Vogel-Fulcher-Tammann-Hesse viscosity equation using correspondence analysis. Physica B: Condensed Matter, v. 398, n. 1, p. 71-77, 2007. https://doi.org/10.1016/j.physb.2007.04.074

[13] Rault, J. Origin of the Vogel-Fulcher-Tammann law in glass-forming materials: The $\beta$ Bifurcation. Journal of Non-Crystalline Solids, v. 271, n. 3, p. 177-217, 2000. https://doi.org/10.1016/S0022-3093(00)00099-5

[14] Garca-Coln, L.S.; Del Castillo, L.F.; Goldstein, P. Theoretical basis for the Vogel-Fulcher-Tammann equation. Physical Review B, n. 41, p. 7040-7044, 1989. https://doi.org/10.1103/PhysRevB.40.7040

[15] Navarro, J.M.F. El vidrio. Consejo Superior de Investigaciones Científicas; 2003. 